Hispania Sacra, LX

121, enero-junio 2008, 47-65, ISSN: 0018-215-X

\title{
LA CURA MONIALIUM EN LOS MONASTERIOS DE MONJAS DOMINICAS DE LA CASTILLA DEL SIGLO XIII: UN ANÁLISIS COMPARATIVO ENTRE DOS COMUNIDADES
}

\author{
POR \\ RitA RÍOS DE LA LLAVE \\ Universidad de Alcalá
}

\section{RESUMEN}

La inserción de comunidades femeninas en la Orden dominicana se vio dificultada por la resistencia de los frailes a hacerse cargo de las monjas, que estaban sometidas a clausura, y necesitaban asistencia espiritual y ayuda en los asuntos temporales. El presente artículo aborda este problema en la Castilla del siglo XIII a través del análisis de la situación en las instituciones fundadas en Madrid y San Esteban de Gormaz -luego trasladada a Caleruega-, que se vieron afectadas por la problemática general, si bien no siempre se ajustaron de forma estricta al modelo establecido por el Papado y aceptado por las autoridades de la Orden para solucionar el conflicto.

PAlABRAS ClAVE: Monjas, Orden dominicana, Clausura, Cura monialium, Reino de Castilla, Siglo XIII

\section{ABSTRACT}

The resistance of the friars to take over the nuns hindered the inclusion of the female communities in the Dominican Order, which were under cloister and needed spiritual assistance and help for their businesses. This article deals with this problem in Castile during the 13th century. The situation in the foundations of Madrid and San Esteban de Gormaz -later moved to Caleruega- is analysed. But, although the general situation affected them, they did not always fit in the model established by the Papacy and accepted by the authorities of the Order so that the conflict could end.

KEY WORDS: Nuns, Dominican Order, Cloister, Cura monialium, Kingdom of Castile, 13th century

Recibido/Received 25-06-2007

Aceptado/Accepted 129-07-2007 


\section{INTRODUCCIÓN}

Uno de los factores que explica la escasez de comunidades monásticas femeninas pertenecientes a la Orden de los Frailes Predicadores en el reino castellano-leonés durante la Edad Media es el problema de la cura monialium. Esta expresión hace referencia a la negativa de los dominicos a hacerse cargo de la atención espiritual y del cuidado de los asuntos temporales de las monjas, algo que resultaba fundamental para ellas, ya que las autoridades eclesiásticas entendían que no podían valerse por sí mismas, al estar sometidas a clausura.

Desde que, en el año 1298, Bonifacio VIII promulgó la Decretal Periculoso, en la que ordenaba el enclaustramiento de todas las monjas ${ }^{1}$, la clausura se convirtió en una práctica obligatoria para las mujeres consagradas a la vida religiosa. Fue ésta una institución importante en la Iglesia desde los primeros tiempos del cristianismo. Ya antes de la intervención papal hubo algunas órdenes monásticas cuyas integrantes adoptaron este elemento como parte de su forma de vida, caso de las dominicas.

El encerramiento de las monjas hacía necesaria la presencia en los monasterios de alguien que se ocupase de la atención espiritual y de la administración de sus bienes, tarea que, en el caso de las dominicas, se encomendó a los dominicos. Pero la proliferación de las fundaciones femeninas dificultaba a los frailes el ejercicio de sus tareas, especialmente la predicación. Por ello se negaron a ocuparse de las monjas. Esta actitud creó un problema muy grave, que se prolongó durante gran parte del siglo XIII, y que desempeñó un papel determinante en el proceso de incorporación de comunidades femeninas a la Orden de los Frailes Predicadores en toda Europa ${ }^{2}$.

La Castilla medieval no fue ajena a esta cuestión. Nos proponemos aclararla a través de un análisis comparativo entre dos comunidades concretas, las prime-

\footnotetext{
1 James A. Brundage y Elisabeth M. MAKowsKI, «Enclosure of nuns: the decretal Periculoso and its commentators», Journal of Medieval History 20/2 (1994) pp. 154-155.

2 H. C. Scheeben, «Die Anfänge des zweiten Ordens des hl. Dominikus», Archivum Fratrum Praedicatorum 2 (1932) pp. 284-315. Herbert GRUNDMANn, Movimenti religiosi nel Medioevo. Ricerche sui nessi storici tra l'eresia gli Ordini mendicanti e il movimento religioso femminile nel XII e XIII saecolo e sui presupposti storici della mistica Tedesca, Bolonia, Il Mulino 1980, pp. 215-246 ( $1^{\text {a }}$ edic.: Berlín 1935). Micheline Pontenay de Fontette, Les religieuses à l'âge classique du Droit canon. Recherches sur les structures juridiques des branches féminines des ordres, París, Librairie Philosophique J. Vrin 1967, pp. 115-127. Edward Tracy BRETT, «Humbert of Romans and the Dominican Second Order», Memorie Domenicane, 12. Cultura e istituzioni nell'Ordine domenicano tra Medioevo e Umanesimo. Studi e testi, Pistoia, 1981, pp. 1-25. Luigi CANETTI, «Le ultime volontà di San Domenico. Per la storia dell’Ordo Praedicatorum dal 1221 al 1236», Rivista di storia della Chiesa in Italia 48 (1994) pp. 43-97. Maria Pia Alberzoni, «Papato e nuovi Ordini religiosi femminili», Il Papato Duecentesco e gli Ordini Mendicanti. Atti del XXV Convegno internazionale. Assisi, 13-14 febbraio 1998, Spoleto, Centro Italiano di Studi sull’Alto Medioevo 1998, pp. 205-261.
}

Hispania Sacra, LX

121, enero-junio 2008, 47-65, ISSN: 0018-215-X 
ras instituciones femeninas que la Orden de los Frailes Predicadores tuvo: Santo Domingo el Real de Madrid y Santa María de Castro en San Esteban de Gormaz, trasladada luego a Caleruega, donde quedó establecida definitivamente a partir del año 1270, bajo la advocación de Santo Domingo ${ }^{3}$.

\section{LOS ORÍGENES DE AMBAS COMUNIDADES, LA ADOPCIÓN DE LA CLAUSURA Y LA RETICENCIA DE LA ORDEN}

El Monasterio de Santo Domingo el Real de Madrid fue, inicialmente, una comunidad monástica masculina. Se convirtió en femenina por decisión del fundador de la Orden de Predicadores, durante la visita que realizó por España a finales del año $1218^{4}$. De vuelta a Roma, hacia el año 1220, Domingo de Guzmán envió a las monjas de esta comunidad una carta con instrucciones relativas a la forma de vida que debían seguir. El elemento central era la clausura, que les prohibía salir del monasterio ${ }^{5}$.

Las monjas de San Esteban de Gormaz formaban comunidad al menos desde el año 1229, pero no adoptaron la clausura hasta el año 1238, cuando obtuvieron permiso de Gregorio IX para vivir bajo las Constituciones de San Sixto de Roma ${ }^{6}$. Éstas determinaban que toda mujer que hubiera sido admitida como monja en la Orden dominicana, «domum illam, in qua professionem fecerit,

\footnotetext{
${ }^{3}$ Para la realización de este trabajo se ha consultado la documentación de época medieval perteneciente a ambas instituciones. Los fondos del Monasterio de Santo Domingo el Real de Madrid se conservan en la sección de Clero del Archivo Histórico Nacional (a partir de ahora, AHN). Los fondos del Monasterio de San Esteban de Gormaz se pueden consultar en el Archivo del Monasterio de Santo Domingo de Caleruega (a partir de ahora, AMC). Parte de éstos últimos fueron publicados por Fr. Eduardo Martínez, Colección diplomática del Real Convento de Sto. Domingo de Caleruega, Vergara, El Santísimo Rosario 1931 (a partir de ahora, $C D$ ), y se ha optado por incluir la referencia en esta obra de los documentos citados, siempre que la tengan, para facilitar su consulta.

${ }^{4}$ Lorenzo Galmes y Vito T. Gómez, Santo Domingo de Guzmán. Fuentes para su conocimiento, Madrid, Biblioteca de Autores Cristianos 1987, pp. 795-796. Gerardo DE FRACHET, Vidas de los frailes predicadores, en Miguel Gelabert, José María Milagro y José María De Garganta, Santo Domingo de Guzmán visto por sus contemporáneos, Madrid, Biblioteca de Autores Cristianos 1966, p. 616. Fr. Hernando Del CASTILlo, Primera Parte de la Historia General de Sancto Domingo y de su orden de Predicadores, Madrid, 1584, fol. $83 \mathrm{v}^{\circ}$. Para conocer mejor la historia de esta comunidad monástica en el siglo XIII, vid. Rita Ríos DE LA LlaVe, La implantación de las órdenes mendicantes en Madrid en la Edad Media: Santo Domingo el Real, Memoria de Licenciatura inédita, Alcalá de Henares, 2000.

5 Simon Tugwell, «St. Dominic's letter to the nuns in Madrid», Archivum Fratrum Praedicatorum 56 (1986) pp. 5-13.

6 1) 9-IV-1238: AMC, caj. 7, n 6; CD, doc. CXCII. 2) 12-IV-1238: AMC, caj. 7, n 12; $C D$, doc. CXCIII. Para conocer mejor la historia de esta comunidad monástica, vid. Rita Ríos DE LA LLAVE, $M u$ jeres de clausura en la Castilla medieval. El Monasterio de Santo Domingo de Caleruega, Alcalá de Henares, Universidad de Alcalá 2007.
} 
ullatenus egressura, nisi ad conventum alium eiusdem ordinis ex causa necessaria transferatur ${ }^{7}$. El artículo 15 regulaba todo lo referente a la clausura.

La imposición de la clausura a las monjas implicaba la necesidad de designar a una o varias personas que se encargasen de gestionar los negocios de cada comunidad, y se ocupasen de atender a sus necesidades espirituales. En este sentido, Domingo de Guzmán había dispuesto, en el año 1217, que toda comunidad femenina incorporada a la Orden quedase al cuidado de un grupo de dominicos ${ }^{8}$. Pero las soluciones finalmente adoptadas en Madrid y en San Esteban de Gormaz no se ajustaron a ese modelo, debido a una decisión directa del fundador y/o a la resistencia de los frailes a ejercer la cura monialium.

Según Jordán de Sajonia, Domingo de Guzmán, cuando estaba en su lecho de muerte, recomendó a los frailes que «evitasen todo trato que pudiera parecer sospechoso con mujeres, sobre todo jóvenes» ${ }^{9}$, una afirmación que Luigi Canetti atribuye más a Jordán de Sajonia que a Santo Domingo ${ }^{10}$. En cualquier caso, en el Capítulo General del año 1224 los dominicos decidieron suspender la fundación de instituciones femeninas, e incluso se plantearon la posibilidad de apartar a aquéllas que ya habían sido incorporadas, aunque Gregorio IX no lo permitió. Pero ellos insistieron en el Capítulo General de 1228, y en el de 1235, en el que la Orden prohibió formalmente a los frailes el ejercicio de la cura monialium sobre todas las comunidades de monjas ${ }^{11}$.

\section{LA RESISTENCIA DE LOS FRAILES A ASUMIR EL CUIDADO DE AMBAS COMUNIDADES}

Esta prohibición afectó directamente a la comunidad madrileña, a pesar de que aquí solamente había un fraile al cargo de las dominicas. Así lo había dispuesto el propio Domingo de Guzmán, que había delegado la tarea en su hermano fray Mamés, según informaba a las monjas en la citada carta de 1220. Seguramente detrás de esta decisión existía una motivación práctica: los frailes predicadores llevaban poco tiempo en el reino castellano-leonés, y es de suponer que su número aún era escaso, de tal manera que implicarlos en la cura monialium habría puesto en peligro la implantación de la Orden ${ }^{12}$. De todos mo-

\footnotetext{
${ }^{7}$ Constituciones de San Sixto de Roma (a partir de ahora CSR), art. 2, en Gelabert, Milagro y GARGANTA, op. cit., p. 792.

${ }^{8}$ SCHEEBEN, op. cit., p. 305.

9 Jordán De Sajonia, Orígenes de la Orden de Predicadores, cap. LIV, en Gelabert, Milagro y GARGANTA, op. cit., p. 176.

${ }^{10}$ CANETTI, op. cit., pp. 65 y 83.

${ }^{11}$ Pontenay De FonTetTe, op. cit., p. 117.

12 En agosto de 1217, y ante el peligro de que la ciudad de Tolosa fuera asediada, Domingo decidió dispersar a sus discípulos, y a España envió un grupo pequeño, formado por cuatro frailes (Marie Hum- 
dos, fray Mamés no debió permanecer en Madrid más allá del año 1234, fecha de la canonización del fundador de la Orden de los Predicadores, pues, según cuenta fray Rodrigo de Cerrato, fue entonces cuando el hermano de Domingo de Guzmán se trasladó a Caleruega, para promover la fundación de una iglesia en el lugar de nacimiento del nuevo santo ${ }^{13}$.

La marcha de fray Mamés a Caleruega y la prohibición del Capítulo General de 1235 dejaron a las monjas de Madrid desprovistas de toda ayuda y en una situación un tanto incierta, al igual que ocurrió con otras comunidades de dominicas repartidas por Europa. Muchos monasterios protestaron, y consiguieron que, en 1236, Gregorio IX escribiese al maestro general, Jordán de Sajonia, para que la Orden volviera a atenderlos ${ }^{14}$. Seguramente ése fue el caso del monasterio madrileño, ya que el 7 de abril de ese mismo año Gregorio IX ordenaba al maestro general y al prior provincial de los frailes predicadores en España volver a ocuparse de las monjas de Santo Domingo el Real de Madrid ${ }^{15}$. Pero la orden del Papa no se cumplió.

Decía fray Hernando del Castillo, a finales del siglo XVI, que, en respuesta al Papa, el Capítulo Provincial de los dominicos hispanos celebrado en el año 1238 decidió enviar a Madrid a fray Pedro de Toro, para que actuara como prior de la comunidad, cargo que luego ocupó fray Domingo de Segovia ${ }^{16}$. Sin embargo, la primera alusión a fray Pedro de Toro que se encuentra en la documentación del Monasterio de Santo Domingo el Real de Madrid se retrasa a marzo de 1259, mientras que fray Domingo de Segovia sólo aparece mencionado en julio de ese mismo año, como sustituto de fray Pedro de Toro. Éste se reincorporó luego a su puesto, que ocupó hasta el 1 de mayo de 126317. Estos dominicos, así pues, intervinieron en los asuntos de la comunidad más tarde de lo que señalaba fray Hernando del Castillo, y no pueden relacionarse directamente con la bula otorgada por Gregorio IX en el año 1236.

Resulta indudable la presencia de frailes dominicos en la comunidad madrileña, según revelan los documentos relativos a los negocios jurídicos de las

\footnotetext{
bert Vicaire, Histoire de Saint Dominique: 2. Au coeur de l'Église, París, Les Editions du Cerf 1982, pp. 89-91 y 95).

${ }^{13}$ Rodrigo de CerRato, Vida de Santo Domingo, en Galmes y Gómez, op. cit., p. 363. Fray Rodrigo de Cerrato debió conocer estos hechos a través de las monjas de Caleruega, cuyo monasterio visitó, ya que aparece como testigo en un acuerdo entre la comunidad y don Benito, clérigo de la villa, redactado el 26 de marzo de 1272 (AMC, caj. 7, n 23; CD, doc. CCXLIV).

${ }^{14}$ SCHEEBEN, op. cit., p. 312.

15 Tomás RiPoll, Bullarium Ordinis FF. Praedicatorum, Roma, 1729, t. I, p. 87: Gregorio IX, $\mathrm{n}^{\circ}$ CLIII (7-IV-1236).

${ }^{16}$ DEL CASTILlo, op. cit., fol. $87 \mathrm{v}^{\circ}$.

17 1) III-1259: AHN, sec. Clero, carp. 1354, doc. 2. 2) VII-1259: AHN, sec. Clero, carp. 1354, doc. 5. 3) 1-V-1263: AHN, sec. Clero, carp. 1354, doc. 19.
} 
monjas. Entre los años 1238 y 1246, figura un tal fray Sancho como representante de la comunidad, principalmente a la hora de comprar propiedades, bajo el cargo de procurador o provisor, bien solo, bien acompañando a alguna de las prioras ${ }^{18}$. Su papel, sin embargo, no puede ser considerado consecuencia de la bula de 1236, dado que, antes de esta fecha había actuado ya del mismo modo ${ }^{19}$. Así pues, los frailes no se desvincularon completamente de las dominicas madrileñas, puesto que al menos uno de ellos les prestaba ayuda en sus negocios jurídicos. Pero esta circunstancia no está relacionada con la carta de Gregorio IX en 1236 y, en cualquier caso, no supuso para los frailes asumir la cura monialium.

La relación entre las monjas de Madrid y los frailes predicadores tampoco se alteró por efecto de las decisiones posteriores, pues mientras el Papa dispensaba de la cura monialium a los dominicos en 1239, fallo que fue ratificado en 1243 por Inocencio IV ${ }^{20}$, fray Sancho siguió interviniendo en los asuntos del Monasterio de Santo Domingo el Real hasta el año 1246. Todo lleva a pensar que había al menos un dominico ocupándose de los asuntos de las monjas madrileñas, al margen de las disposiciones generales y más en consonancia con la carta otorgada por el propio Santo Domingo de Guzmán en el año 1220. Fray Sancho se habría convertido en sucesor de fray Mamés, al menos para las cuestiones prácticas.

Mucho más complicada, si cabe, fue la situación de la comunidad de San Esteban de Gormaz. El Papa Gregorio IX, por mediación del obispo de Osma, solicitó en 1238 al prior provincial de la Orden en España que se ocupase de ellas $^{21}$. Conforme establecían las Constituciones de San Sixto de Roma, que habían decidido adoptar, cuatro religiosos debían ocuparse de los asuntos externos, mientras que seis frailes, de los cuales por lo menos tres tenían que ser sacerdotes, y uno actuar como prior, debían residir en el monasterio para los asuntos espirituales ${ }^{22}$. Era costumbre, en muchos lugares, que el prior provin-

18 1) II-1238: AHN, sec. Clero, carp. 1353, doc. 8. 2) 17-X-1239: AHN, sec. Clero, carp. 1353, doc. 9. 3) 27-X-1239: AHN, sec. Clero, carp. 1353, doc. 10. 4) III-1243: AHN, sec. Clero, carp. 1353, doc. 15. 5) III-1246: Fidel FITA, «Madrid desde el año 1235 hasta el de 1275 . Ilustraciones y texto de la vida de San Isidro por Juan Diácono» (a partir de ahora, M1235), Boletín de la Real Academia de la Historia 9 (1886) p. 24, nº 64. 6) X-1246: AHN, sec. Clero, carp. 1353, doc. 16.

19 VIII-1229: AHN, sec. Clero, carp. 1353, doc. 3. La presencia de fray Sancho en el Monasterio de Santo Domingo el Real de Madrid incluso puede que fuera anterior, ya que figuraba en escrituras del año 1226 (DEL CASTILlo, op . cit., fol. $86 \mathrm{v}^{\circ}$ ), y actuó como procurador en la compra de una propiedad, según un documento fechado en 1225 (Fidel FiTA, «Madrid desde el año 1203 hasta el de 1227» (a partir de ahora, M1203), Boletín de la Real Academia de la Historia 8 (1886) pp. 333-334, n 40).

${ }^{20}$ RIPOLL, op . cit., t. I, p. 107: Gregorio IX, no CXCVI (25-X-1239); y t. I, p. 121: Inocencio IV, $\mathrm{n}^{\circ}$ IX (18-VII-1243).

21 1) 9-IV-1238: AMC, caj. 7, n 6; CD, doc. CXCII. 2) 12-IV-1238: AMC, caj. 7, n 12; $C D$, doc. CXCIII

${ }^{22}$ CSR, art. 18, pp. 807-808.

Hispania Sacra, LX

121, enero-junio 2008, 47-65, ISSN: 0018-215-X 
cial confiase esta responsabilidad al prior del convento masculino más próximo a la comunidad femenina ${ }^{23}$. En el caso de San Esteban de Gormaz, el más cercano era el de San Pablo de Burgos. Pero todo parece indicar que los dominicos de este convento no se encargaron de las monjas, pues, en noviembre de 1239, los frailes burgaleses recibieron la bula que liberaba a todos los dominicos de este tipo de obligaciones ${ }^{24}$. Ni un solo fraile predicador intervino en los negocios jurídicos del monasterio, mientras la comunidad madrileña por lo menos contaba con la colaboración ocasional de fray Sancho.

El interés del Pontificado por los monasterios femeninos de las órdenes mendicantes se reanudó a partir del año 1245, cuando Inocencio IV decidió imponer otra vez, tanto a franciscanos como a dominicos, la cura monialium de sus respectivas comunidades femeninas. La responsabilidad recayó entonces sobre el maestro general y el prior provincial, que debían encargarse personalmente de visitar a las monjas, según consta, en el caso de las dominicas, en una bula fechada el 4 de abril de 1246, que ya tuvieron en cuenta los asistentes al Capítulo Provincial de 124925 .

Esta medida no tuvo efecto en San Esteban de Gormaz. No hay constancia de visitas efectuadas por las autoridades de la Orden, ni siquiera por los dominicos de San Pablo de Burgos, a los que Inocencio IV había reiterado, en octubre de 1246, que no estaban obligados a hacerse cargo de la cura monialium ${ }^{26}$. Ninguna otra comunidad masculina asumió la responsabilidad, como prueba la ausencia de frailes en la documentación monástica. Eso obligó a las monjas a renunciar a la clausura, que no pudieron restablecer hasta el año 1262, cuando fueron reconocidos sus derechos de pertenencia a la Orden de los Frailes Predicadores $^{27}$.

En el monasterio de Madrid no se aprecian cambios al promulgarse la bula de 1246 que encomendaba la cura monialium al maestro general y al prior provincial. A finales de ese año todavía figuraba fray Sancho interviniendo por última vez en los asuntos del monasterio ${ }^{28}$. Tres años después, Inocencio IV se dirigía al prior de la provincia de España, ordenándole hacerse cargo del Monasterio de Santo Domingo el Real de Madrid, y disponiendo que algunos frailes de la Orden se encargasen de visitar a las dueñas, corregirlas, reformar-

\footnotetext{
${ }^{23}$ Gilles MeErsseman, «Les frêres Prêcheurs et le mouvement dévot en Flandre au XIII siècle», Archivum Fratrum Praedicatorum, 18 (1948) p. 96. Pontenay de FontetTe, op. cit., p. 107.

24 16-XI-1239: AHN, Clero, carp. 181, nº 4.

25 RIPOLL, op. cit., t. I, pp. 160-161: Inocencio IV, n CXXXIL (4-IV-1246). Ramón HeRnáNDEZ, «Las primeras Actas de los Capítulos Provinciales de la Provincia de España», Archivo Dominicano 5 (1984) p. 26.

26 15-X-1246: AHN, Clero, carp. 181, n 11

27 24-V-1262: AMC, caj. 12, n 61b; $C D$, doc. CCXXIV.

${ }^{28}$ X-1246: AHN, sec. Clero, carp. 1353, doc. 16.
} 
las, escuchar sus confesiones y administrarles los sacramentos ${ }^{29}$. Modificaba así lo dispuesto en la bula de 1246, porque ya no era una responsabilidad directa del prior provincial, sino que éste delegaba la tarea en otros frailes. Pero aseguraba, al menos, que alguien se ocupara de las monjas.

De todos modos esta nueva disposición tampoco tuvo un efecto real, pues ningún dominico intervino en la vida del Monasterio de Santo Domingo el Real de Madrid hasta el año 1252, cuando se menciona a fray Romero ${ }^{30}$. El dato, sin embargo, es importante, a pesar del retraso, sobre todo si se tiene en cuenta que, precisamente ese mismo año, la situación había vuelto a cambiar para los monasterios de dominicas. De nuevo el Capítulo General de la Orden de los Frailes Predicadores, con el consentimiento del Papa, rechazaba atender a las monjas ${ }^{31}$. La medida no afectaba a la institución madrileña. Pero es verdad que la presencia del fraile era meramente testimonial y no hay constancia de que algún miembro de la Orden estuviera al cargo del monasterio madrileño.

Poco después, la actitud de Inocencio IV respecto a la cura monialium volvía a cambiar y, en el año 1254, encomendaba al cardenal dominico Hugo de San Caro la resolución del problema. Pero fue el maestro general de los predicadores, Humberto de Romans, quien, en 1255, hizo una propuesta aceptada por el Capítulo General: sería éste último quien podría aprobar una nueva fundación, que sólo quedaría plenamente incorporada a la Orden tras ser aprobada en tres capítulos consecutivos. La medida dio lugar a numerosas peticiones de incorporación por parte de las comunidades femeninas, y los dominicos pronto se vieron desbordados, de manera que, en 1257, pidieron a Alejandro IV ser nuevamente liberados del ejercicio de la cura monialium El Papa lo aceptó, aunque con una excepción: tendrían que seguir al cargo de aquellos monasterios femeninos que hubieran sido establecidos por el propio Santo Domingo de Guzmán ${ }^{32}$.

En esa situación se encontraba la comunidad de Santo Domingo el Real de Madrid. Pero por si acaso hubiera alguna duda, el Papa se encargó, en el año 1258 , de otorgar a las monjas madrileñas una nueva bula, indicando expresamente «Cum itaque vos, prout accepimus, secundum Instituta dilectorum filiorum Fratrum Ordinis Predicatorum, sub eorum cura et etiam sub clausura vivatis» ${ }^{33}$. Fue entonces cuando los dominicos asumieron la cura monialium de la

${ }^{29} \mathrm{La}$ bula de Inocencio IV fechada el 27 de abril de 1249 se ha conservado inserta en un traslado del 24 de abril de 1346 (AHN, sec. Clero, carp. 1359, doc. 21).

${ }^{30}$ Fray Romero figura como prior en dos documentos: 1) XI-1252: AHN, sec. Clero, carp. 1353, doc. 18. 2) II-1257: AHN, sec. Clero, carp. 1353, doc. 19.

${ }^{31}$ RIPOLL, op. cit., t. I, pp. 217-218: Inocencio IV, n ${ }^{\circ}$ CCLXIX (26-IX-1252).

32 Pontenay de Fontette, op. cit., pp. 122-123. Ripoll, op. cit., t. I, p. 354: Alejandro IV, $n^{\circ}$ CLXXXIX (16-XI-1257).

${ }^{33}$ La bula de Alejandro IV, fechada el 13 de junio de 1258, aparece inserta en un traslado del 24 de abril de 1346 (AHN, sec. Clero, carp. 1359, doc. 21).

Hispania Sacra, LX

121, enero-junio 2008, 47-65, ISSN: 0018-215-X 
comunidad de Santo Domingo el Real de Madrid. Lo prueba la presencia de un prior al frente de las monjas desde marzo de $1259^{34}$.

La excepción señalada por Alejandro IV en 1257, en cambio, no beneficiaba a las monjas de San Esteban de Gormaz, dado que su comunidad no había sido establecida por el fundador de la Orden de los Predicadores, a pesar de que se afirmara luego lo contrario. Tuvieron que esperar a la resolución del Capítulo General de 1259, en el que Humberto de Romans consiguió que la Orden de Predicadores se encargara de todas las instituciones femeninas que contaran con la aprobación de un prior provincial, un maestro general, un capítulo general o un Papa ${ }^{35}$.

En fecha indeterminada, pero en cualquier caso anterior a 1261, las monjas de San Esteban solicitaron al propio fray Humberto poder regirse por las Constituciones que él había elaborado y que habían sido presentadas en el mismo Capítulo General de 1259. La solicitud dio lugar a una investigación, que fray Humberto confió a fray Raimundo de Peñafort, y que éste, enfermo, delegó en fray Rodrigo de Atienza. Tras escuchar los testimonios de éste último, de las interesadas, de los definidores del Capítulo Provincial de Zamora de 1261 y de los priores de varios conventos catalanes, Raimundo de Peñafort dio por cierto que la comunidad había sido acogida en la Orden por el propio Domingo de Guzmán y por los maestros generales Jordán de Sajonia y Juan el Teutónico, además de contar con la autorización del Papa Gregorio IX. En realidad, sólo puede asegurarse que las monjas contaron con el apoyo papal, argumento que hubiera bastado por sí solo para conseguir el reconocimiento, que finalmente obtuvieron en 1262, cuando fueron acogidas en la Orden y su cuidado, confiado al prior provincial ${ }^{36}$. De todos modos, los frailes siguieron sin hacer acto de presencia hasta que, en 1266, empezó a prepararse el traslado de la comunidad a Caleruega ${ }^{37}$.

Así pues, los dominicos asumen la cura monialium de la comunidad madrileña en 1258, y desde 1262 en el de la de San Esteban de Gormaz. Pudieron las monjas entonces, finalmente, incorporar plenamente la clausura a su forma de vida, y, conforme a una nueva normativa de 1259, las Constituciones de Humberto de Romans, que prohibían el abandono del monasterio, bajo pena de anatema, excepto en caso de «periculum ignis, uel ruine, uel latronum seu malefac-

${ }^{34}$ AHN, sec. Clero, carp. 1354, doc. 2.

35 Pontenay de Fontette, op. cit., p. 124.

36 1) 24-III-1261: AMC, caj. 12, n 61a; CD, doc. CCXXIII. 2) 24-V-1262: AMC, caj. 12, n 61b; $C D$, doc. CCXXIV. 3) 10-VI-1262: AMC, caj. 12, n 61c; $C D$, doc. CCXXV. 4) 12-VII-1262: AMC, caj. $12, \mathrm{n}^{\circ} 61 \mathrm{~d} ; C D$, doc. CCXXVI. Sobre los problemas que plantea la presunta admisión de las monjas de San Esteban de Gormaz por Domingo de Guzmán, Jordán de Sajonia y Juan el Teutónico, vid. Ríos de la LlaVe, Mujeres de clausura..., pp. 61-65 y 92-93.

37 31-X-1266: AMC, caj. 1, n 3; $C D$, doc. IX. 
torum, aut similium euentuum, qui solent uergere in periculum mortis» ${ }^{38}$, pero se permitía al maestro general autorizar el traslado de una monja a otra casa. A partir de ese momento, alguien debía ocuparse del cuidado espiritual y de los negocios temporales de las monjas. Y los frailes empezaron a actuar desde 1259 en Santo Domingo el Real de Madrid, mientras que en Santa María de Castro no lo hicieron hasta 1266.

EL EJERCICIO DE LA CURA MONIALIUM EN AMBAS COMUNIDADES HASTA FINALES DEL SIGLO XIII

Vamos a definir ahora el papel de los dominicos con respecto a la curia monialium durante el siglo XIII, tanto en la comunidad de Santo Domingo el Real de Madrid como en la de Santo Domingo de Caleruega, surgida a partir de la de San Esteban de Gormaz. Fue una labor en la que, como se verá, al final se vieron implicados también otros sectores eclesiásticos, cuyo trabajo también se ha analizado.

En las Constituciones de Humberto de Romans, en vigor desde 1259, y a diferencia de las de San Sixto de Roma adoptadas en San Esteban de Gormaz, no se determinaba la presencia en el monasterio de un número determinado de frailes que se ocupasen de los asuntos temporales y de la atención espiritual de las monjas. No resulta extraño, si se tiene en cuenta que habían sido redactadas en medio del conflicto planteado por la cura monialium. De ahí la prudencia en permitir a los frailes de la Orden únicamente administrar a las monjas dos sacramentos, confesión y comunión ${ }^{39}$. Pero en muchas comunidades fue frecuente que los asuntos de las monjas estuvieran en manos de un prior y de algunos frailes (procurador, confesores, conversos, etc. ${ }^{40}$, que se ocupaban de las necesidades espirituales de las monjas, administraban sus bienes, y representaban y defendían sus derechos. Para el siglo XIII, encontramos en la documentación del monasterio madrileño procuradores, provisores y priores, y otros frailes sin cargo asignado, mientras que en la de Caleruega figura un solo prior y varios dominicos sin oficio específico.

Parece que el término procurador define a la persona encargada de todos los asuntos relativos a la administración del patrimonio de los monasterios femeninos, incluyendo la dirección del personal que trabajaba en las explotaciones

\footnotetext{
38 Vid. Constituciones de Humberto de Romans en P. MотноN (ed.), «Liber Constitutionum Sororum Ordinis Praedicatorum», Analecta Sacri Ordinis Fratrum Praedicatorum = Vetera Monumenta Legislativa Sacri Ordinis Praedicatorum ex saeculo a Nativitate Christi tertio decimo, ordinis primo 2-3 (1897-1898) pp. 337-348 (a partir de ahora $L C S$ ). La cita procede del cap. XXIX, pp. 347-348.

39 Ibidem, cap. XII, p. 341.

${ }^{40}$ Pontenay de Fontette, op. cit., p. 116.

Hispania Sacra, LX

121, enero-junio 2008, 47-65, ISSN: 0018-215-X
} 
agrícolas ${ }^{41}$. En este sentido cabe entender la actuación de fray Sancho, el único dominico que figura indistintamente como procurador o provisor de las monjas de Madrid hasta el año 1246. Actuando de forma individual o acompañando a la priora, se encarga de comprar propiedades destinadas a la comunidad ${ }^{42}$, o de efectuar alguna permuta ${ }^{43}$.

El término prior se aplica a la persona que está al frente de una comunidad masculina y, a veces, también, de una comunidad femenina, que administra tanto desde el punto de vista temporal como espiritual ${ }^{44}$. En Caleruega, el único prior de la comunidad que figura para el siglo XIII, fray Juan Gil, representa a la priora en una permuta efectuada en 1274, mientras que en 1276 interviene, junto a otros frailes, como testigo en una venta ${ }^{45}$. En Santo Domingo el Real de Madrid está probada la presencia del prior a partir del año $1252^{46}$, pero su papel no queda definido sino a partir del año 1259. Como lo hizo antes el procurador o provisor, interviene en los negocios jurídicos del monasterio. Actuando a título individual o principalmente acompañando a alguna de las prioras, los frailes que ocuparon este cargo hasta finales del siglo XIII, compraron propiedades para las monjas ${ }^{47}$, recibieron bienes donados al monasterio ${ }^{48}$, realizaron permutas de propiedades conventuales ${ }^{49}$, las autorizaron ${ }^{50}$, intervinieron como testi-

41 Ibidem, p. 108.

42 1) 6-I-1225: FITA, M1203, pp. 333-334, n 40. 2) VIII-1229: AHN, sec. Clero, carp. 1353, doc. 3. 3) II-1238: AHN, sec. Clero, carp. 1353, doc. 8. 4) 17-X-1239: AHN, sec. Clero, carp. 1353, doc. 9. 5) III-1243: AHN, sec. Clero, carp. 1353, doc. 15. 6) III-1246: FITA, M1235, p. 24, n 64. 7) X-1246: AHN, sec. Clero, carp. 1353, doc. 16.

43 27-X-1239: AHN, sec. Clero, carp. 1353, doc. 10.

44 Pontenay de FontetTe, op. cit., pp. 104-105. CCLII.

45 1) 5-XII-1274: AMC, caj. 7, n 16; $C D$, doc. CCL. 2) 31-XII-1276: AMC, caj. 7, n 15; $C D$, doc.

46 1) XI-1252: AHN, sec. Clero, carp. 1353, doc. 18. 2) II-1257: AHN, sec. Clero, carp. 1353, doc. 19. En ambos documentos se hace referencia al mismo prior, fray Romero.

47 1) III-1259: AHN, sec. Clero, carp. 1354, doc. 2. 2) 29-IV-1259: AHN, sec. Clero, carp. 1354, doc. 3. 3) V-1259: AHN, sec. Clero, carp. 1354, doc. 4. 4) V-1259: AHN, sec. Clero, carp. 1354, doc. 10. 5) 3-V-1260: AHN, sec. Clero, carp. 1354, doc. 10bis. 6) 26-VII-1260: FITA, M1235, pp. 49-50, $n^{\circ}$ 79. 7) 2-VIII-1260: AHN, sec. Clero, carp. 1354, doc. 11. 8) 16-I-1261: AHN, sec. Clero, carp. 1354, doc. 12. 9) 20-VII-1261: AHN, sec. Clero, carp. 1354, doc. 13. 10) 13-XI-1261: AHN, sec. Clero, carp. 1354, doc. 14. 11) 22-II-1262: AHN, sec. Clero, carp. 1354, doc. 15. 12) 18-III-1262: AHN, sec. Clero, carp. 1354, doc. 16. 13) 16-X-1262: AHN, sec. Clero, carp. 1354, doc. 17. 14) 12-IV-1263: AHN, sec. Clero, carp. 1354, doc. 18. 15) 1-V-1263: AHN, sec. Clero, carp. 1354, doc. 19. 16) 3-VII1267: AHN, sec. Clero, carp. 1355, doc. 1. 17) 26-III-1284: AHN, sec. Clero, carp. 1356, doc. 3. 18) 14-IV-1299: AHN, sec. Clero, carp. 1357, doc. 15.

48 1) 29-XII-1273: AHN, sec. Clero, carp. 1355, doc. 14. 2) 5-III-1293: AHN, sec. Clero, carp. 1357, doc. 9 .

49 1) Sin fecha: AHN, sec. Clero, carp. 1357, doc. 18. 2) 11-VI-1298: AHN, sec. Clero, carp. 1357 , doc. 14 .

50 14-II-1283: AHN, sec. Clero, carp. 1355, doc. 19. 
gos en las mismas ${ }^{51}$, y efectuaron particiones de bienes pertenecientes a la comunidad ${ }^{52}$. Todo indica, así pues, que, a partir del año 1259, el prior relevó a la figura del provisor o procurador, justo en el momento en que los frailes dominicos asumieron plenamente la cura monialium de Santo Domingo el Real de Madrid. Además, y dado que las monjas estaban sometidas a clausura, su presencia resultaba necesaria en cualquier negocio de la comunidad. Cuando el prior no podía asumir sus funciones, podía ser sustituido por otro fraile que actuaba como «tenedor delas uezes del prior» ${ }^{53}$.

Por tanto, es evidente que los priores de las comunidades de Caleruega y Madrid se hicieron cargo de los asuntos temporales de las monjas. Pero no fueron los únicos, tal y como demuestra la actuación de frailes que, en principio, no tenían asignado un cargo específico.

Cuando la priora doña Toda Martínez tomó posesión de Caleruega, el 31 de octubre de 1266, estaban presentes algunos frailes de Burgos, como el prior fray Sancho, fray Rodrigo de Atienza, fray Cornejo y fray Bartolomé, y otros frailes de la Orden presenciaron la entrada de la comunidad en el monasterio, el 11 de julio de 1270. Dos años después, seis frailes figuraban como testigos en una avenencia, entre ellos un tal fray Domingo de Caleruega, el prior de Madrid y fray Rodrigo de Cerrato. Y en 1273 la priora doña Toda Martínez enviaba a dos dominicos hasta Soria para que la representasen en los asuntos de la herencia de su padre ${ }^{54}$.

Desde entonces aparecen con frecuencia algunos frailes como testigos en acuerdos, permutas, compra-ventas y cartas enviadas al Papa, a veces actuando en grupos de tres o cinco ${ }^{55}$. Se puede decir que la asistencia de los frailes se había vuelto habitual en Caleruega, algo que fray Munio de Zamora quiso sancionar con sus Ordenaciones de 1288, que vinieron a imponer en el monasterio de Caleruega la presencia continuada de un grupo de dominicos, «qui uobis ecclesiastica sacramenta ministrent, et uestras confessiones audiant, uestrisque ne-

51 19-III-1294: AHN, sec. Clero, carp. 1357, doc. 10.

52 Sin fecha: AHN, sec. Clero, carp. 1357, doc. 19a.

${ }^{53}$ Es el caso de fray Domingo Muñoz de Segovia, que compra una propiedad en julio de 1259 en sustitución del prior fray Pedro de Toro (AHN, sec. Clero, carp. 1354, doc. 5). También el de fray Gil, que adquiere cierto bien, el 30 de septiembre de 1266, reemplazando al mismo prior antes mencionado (AHN, sec. Clero, carp. 1354, doc. 20).

54 1) 31-X-1266: AMC, caj. 1, n 3; CD, doc. IX. 2) 11-VII-1270: Inserto en AMC, caj. 1, $\mathrm{n}^{\circ} 4$; $C D$, doc. XIII. 3) 26-III-1272: AMC, caj. 7, n 23; CD, doc. CCXLIV. 4) 23-VI-1273: AMC, caj. 7, $\mathrm{n}^{\circ} 23$ bis; $C D$, doc. CCXLV.

55 1) 21-II-1274: AMC, caj. 12, n 37; CD, doc. CCXLVI. 2) 5-XII-1274: AMC, caj. 7, n 16; $C D$, doc. CCL. 3) 31-XII-1276: AMC, caj. 7, n 15; CD, doc. CCLII. 4) 13-II-1278: AMC, caj. 7, n 14; $C D$, doc. CCLV. 5) 12-IX-1283: AMC, caj. 6, n² 24; CD, doc. CCLVIII. 6) 11-VI-1285: AMC, caj. 12, $\mathrm{n}^{\circ} 3 ; C D$, doc. CCLIX.

Hispania Sacra, LX

121, enero-junio 2008, 47-65, ISSN: 0018-215-X 
gotiis asistant, tam spiritualibus quam temporalibus procurandis» ${ }^{56}$. Ahora bien, aunque los frailes asistían a las monjas, no se instalaron en el monasterio hasta el siglo XIV.

Por lo que se refiere a Santo Domingo el Real de Madrid, en el año 1232, cuando fray Mamés todavía debía estar al cargo de las monjas madrileñas, encontramos a fray Domingo Pelagii actuando como notario, y encargándose de la redacción de un documento para una permuta de unas tierras en Corralejos ${ }^{57}$. En el año 1284, los frailes predicadores de Toledo interceden, ante el concejo de Toledo, para que éste conceda exención de montazgo en todos sus extremos al ganado y a los pastores de las dominicas madrileñas ${ }^{58}$. Más adelante, en 1293 , la priora y el prior de Santo Domingo el Real de Madrid ceden a un particular un heredamiento en Rabudo y Carabanchel que pertenecía a un tal fray Gil ${ }^{59}$. Al año siguiente, el dominico fray Gil de Alba, seguramente el mismo fraile que se acaba de mencionar, figuraba como testigo en una operación de cambio realizada por la priora Urraca ${ }^{60}$.

La documentación, por tanto, refleja una clara vinculación entre las dominicas y los frailes predicadores, si bien la colaboración de éstos siempre estuvo centrada en aspectos relativos a los negocios y a la gestión del patrimonio. Ni siquiera constan referencias a esas dos funciones de tipo espiritual, la administración de la confesión y la comunión, impuestas a los frailes las Constituciones de Humberto de Romans, obligatorias para todas las comunidades de dominicas desde el año 1259, y que, en el caso de Caleruega, habían sido ratificadas por las Ordenaciones de fray Munio de Zamora de 1288.

Es posible que la atención espiritual la hubieran prestado clérigos que frecuentaban los monasterios y, conforme a lo que dispuso Clemente IV en la bula del año 1267 que resolvió definitivamente, en la Orden de los Frailes Predicadores, el problema de la cura monialium $^{61}$. El Papa ordenaba al maestro general y a los priores provinciales de los dominicos asumir la cura monialium, descrita entonces como la obligación de visitar, corregir y reformar a las monjas, así como el derecho a nombrar o destituir a la priora, y prohibía asimismo a los frailes residir de forma continuada en los monasterios femeninos, algo que no se respetó en Caleruega, a partir del siglo XIV. Los asuntos espirituales de las monjas, especialmente la administración de los sacramentos, eran confiados a capellanes seculares.

\footnotetext{
56 AMC, caj. 11, n 20; CD, doc. CCLXI.

57 AHN, sec. Clero, carp. 1353, doc. 7.

58 4-VII-1284: AHN, sec. Clero, carp. 1356, doc. 4.

59 5-III-1293: AHN, sec. Clero, carp. 1357, doc. 9.

60 19-III-1294: AHN, sec. Clero, carp. 1357, doc. 10.

${ }^{61}$ RiPOLL, op. cit., t. I, pp. 481-482: Clemente IV, nº LIX (6-II-1267).
} 
Esta especie de reparto de funciones ya ha sido analizada en el caso de alguna comunidad de monjas dominicas del territorio hispano ${ }^{62}$. Y es posible que también se hubiese decidido adoptar esta medida en las dos instituciones objeto de este trabajo, dado que en la documentación de la segunda mitad del siglo XIII trasciende con frecuencia la presencia de clérigos ajenos a la Orden dominicana.

Así, en el Monasterio de Santo Domingo el Real de Madrid encontramos a clérigos de las parroquias de la villa actuando como testigos en los negocios jurídicos del monasterio $0^{63}$. No suele precisarse el cargo que ocupaban, aunque hay algunos diáconos ${ }^{64}$, subdiáconos ${ }^{65}$ y sacristanes ${ }^{66}$. Hasta los años sesenta predominan los clérigos de las parroquias de San Juan ${ }^{67}$, Santiago ${ }^{68}$, y San Nicolás ${ }^{69}$, todas ellas ubicadas dentro de la villa, y también los de San Ginés, situada extramuros ${ }^{70}$. Antes de la bula de 1267, las dominicas madrileñas se habían visto obligadas a recurrir a los servicios de los clérigos de todas estas

62 Clara Rodríguez NúÑEZ, El monasterio de dominicas de Belvís de Santiago de Compostela, separata de Estudios Mindonienses 5 (1990) p. 25.

${ }^{63}$ Sólo en tres ocasiones aparece como testigo un miembro del clero que no es de la villa de Madrid: en mayo de 1219, Pedro Feliz, diácono de San Salvador de Toledo (documento que reproduce Jerónimo DE Quintana, A la muy Antigua, Noble y Coronada Villa de Madrid. Historia de su antigüedad, nobleza y grandeza, Madrid, 1629 (edic. facs.: Madrid, 1986), t. II, fol. 392 vº el 14 de marzo de 1272, Diego, clérigo de Carrascalejo (AHN, sec. Clero, carp. 1355, doc. 6); y el 22 de septiembre de 1283, Benito, clérigo de Getafe (AHN, sec. Clero, carp. 1356, doc. 2).

64 1) V-1219: Clemente, en Santiago; Garci Martínez, en San Juan; Pedro Feliz, en San Salvador de Toledo (DE QuinTANA, op. cit., t. II, fol. 392 vo ). 2) 20-IV-1236: Asensio, en San Andrés (AHN, sec. Clero, carp. 1353, doc. 7ter).

65 V-1219: Abril, en San Salvador; Andrés, en Santiago; y Pedro García, en Santa María (DE QuINTANA, op. cit., t. II, fol. $392 \mathrm{v}^{\mathrm{o}}$ ).

66 1) IX-1232: Sancho, en San Ginés (AHN, sec. Clero, carp. 1353, doc. 6). 2) 4-IX-1285: Diago Pérez, en San Salvador (AHN, sec. Clero, carp. 1356, doc. 18). 3) 6-IX-1285: Miguel Fernández, en San Ginés (AHN, sec. Clero, carp. 1356, doc. 19).

67 1) V-1219: Garci Martínez, diácono (DE Quintana, op. cit., t. II, fol. 392 vº). 2) 6-I-1243 y V1247: Martín, clérigo (AHN, sec. Clero, carp. 1353, doc. 14ter y doc. 17). 3) 6-I-1243: Lázaro, clérigo (AHN, sec. Clero, carp. 1353, doc. 14ter). 4) II-1257: Juan García Gómez, clérigo (AHN, sec. Clero, carp. 1353, doc. 19). 5) 29-IV-1259: Rodrigo, racionero (AHN, sec. Clero, carp. 1354, doc. 3).

68 1) V-1219: Andrés, subdiácono (DE QUINTANA, op. cit., t. II, fol. 392 v $^{\circ}$ ). 2) V-1219: Clemente, diácono (Idem). 3) I-1233: Alfonso, clérigo (AHN, sec. Clero, carp. 1353, doc. 7bis). 4) 17-X-1239: Pedro, clérigo (AHN, sec. Clero, carp. 1353, doc. 9). 5) 17-IV-1247: Aparicio de Santiago (FITA, M1235, pp. 26-27, no 65/d). 6) 29-VIII-1259: Agustín Pérez, clérigo (AHN, sec. Clero, carp. 1354, doc. 7). 7) 29-VIII-1259 y 13-XI-1261: Domingo Illán, clérigo (Idem y AHN, sec. Clero, carp. 1354, doc. 14).

69 1) 3-IV-1241, V-1242 y 10-VIII-1245: Pedro Vicente, clérigo (AHN, sec. Clero, carp. 1353, doc. 11 y doc. 13; FITA, M1235, pp. 23-24, n 63). 2) II-1257: Domingo Salvador, clérigo (AHN, sec. Clero, carp. 1353, doc. 19).

70 1) IX-1232: Juan, clérigo (AHN, sec. Clero, carp. 1353, doc. 6). 2) IX-1232: Sancho, sacristán (Idem).

Hispania Sacra, LX

121, enero-junio 2008, 47-65, ISSN: 0018-215-X 
parroquias, las más próximas al Monasterio de Santo Domingo. Aunque hay una excepción notable: no se detecta la presencia de los miembros de San Martín, monasterio que daba su nombre a una collacion extramuros de la villa, y que se encontraba muy próximo al edificio de las dominicas ${ }^{71}$. Éstas últimas, así pues, se servían del clero de las parroquias más cercanas, sobre todo de aquéllas que estaban situadas dentro del recinto urbano.

Desde los años sesenta, precisamente una vez que los frailes dominicos ejercen la cura monialium, se produce un cambio. De forma aislada, figuran los clérigos de San Nicolás ${ }^{72}$, San Juan ${ }^{73}$ y San Ginés ${ }^{74}$. Predominan ahora los que proceden de la parroquia de San Salvador ${ }^{75}$, que antes de esa época sólo habían aparecido de forma ocasional ${ }^{76}$. Esta parroquia estaba más lejos del Monasterio de Santo Domingo que las otras, pero era la más importante de la villa, dado que allí tenía su sede el concejo. Es probable que las dominicas decidieran recurrir a los clérigos de San Salvador, a partir de los años sesenta, como una forma de conseguir el apoyo de los sectores sociales más influyentes en la institución municipal para la construcción del nuevo monasterio que acababan de iniciar, o quizás porque existía una vinculación importante entre la Orden de los dominicos y el clero de la parroquia más importante de Madrid ${ }^{77}$.

En la comunidad de Caleruega, se detecta también la presencia de clérigos de las parroquias locales desde antes del reparto de funciones establecido en la bula de Alejandro IV de 1267. Esta vinculación, de hecho, había comenzado ya durante el período en el que las monjas residieron en San Esteban de Gormaz. $\mathrm{Al}$ igual que habíamos visto en el caso de Madrid, tampoco suele precisarse el

${ }^{71}$ Manuel Montero Vallejo, El Madrid medieval, Madrid, El Avapiés 1992 (1ª edic. 1987), pp. $162-167$.

72 7-VII-1297: Martín Martínez, clérigo (AHN, sec. Clero, carp. 1357, doc. 13).

73 1) 1-VII-1291: Juan Domínguez, clérigo (AHN, sec. Clero, carp. 1357, doc. 8). 2) 1-VII-1291: Pascual Pérez, clérigo (Idem).

74 1) 29-IV-1259 y 24-X-1277: Juan Pérez, racionero (AHN, sec. Clero, carp. 1354, doc. 3; AHN, sec. Clero, carp. 1355, doc. 13). 2) 6-IX-1285: Miguel Fernández, sacristán (AHN, sec. Clero, carp. 1356, doc. 19). 3) 6-IX-1285 y 19-III-1294: Domingo García, clérigo (Idem y AHN, sec. Clero, carp. 1357, doc. 10).

75 1) 26-VII-1260: Diago, clérigo (FITA, M1235, pp. 49-50, no 79). 2) 2-VIII-1260, 16-X-1262 y 24-X-1277: Juan Pérez, clérigo (AHN, sec. Clero, carp. 1354, doc. 11 y doc. 17, y carp. 1355, doc. 13). 3) 2-VIII-1260: García Vicente, clérigo (AHN, sec. Clero, carp. 1354, doc. 11). 4) 16-X-1262, 12-IV1263 y 14-III-1272: Juan Esteban, clérigo (AHN, sec. Clero, carp. 1354, doc. 17 y doc. 18, y carp. 1355, doc. 6). 5) 29-XII-1273: Alfonso Pérez, clérigo (AHN, sec. Clero, carp. 1355, doc. 14). 6) 4-IX1285: Diago Pérez, sacristán (AHN, sec. Clero, carp. 1356, doc. 18). 7) 6-I-1287: Fernando Sánchez, clérigo (AHN, sec. Clero, carp. 1357, doc. 2).

76 1) V-1219: Abril, subdiácono (DE QuINTANA, op. cit., t. II, fol. 392 vº. 2) III-1243: Diago, clérigo (AHN, sec. Clero, carp. 1353, doc. 15). 3) III-1243 y 16-V-1254: Juan Pérez, clérigo (Idem y FITA, M1235, pp. 37-38, n 71).

77 Ríos DE LA LlaVe, La implantación ..., pp. 112-114. 
cargo que ocupaban estos clérigos, habiendo igualmente sacristanes ${ }^{78}$, diáconos y subdiáconos ${ }^{79}$, y también algún campanero y algún canónigo ${ }^{80}$.

Los primeros clérigos los mencionan un documento de 1260, en el que aparece Pascual Yáñez, de la iglesia de San Miguel, al que las monjas ceden temporalmente unas hazas de pan llevar, actuando como testigos otros dos clérigos, adscritos a la iglesia de Santa Olalla: Fernando Yáñez y Domingo Martínez. A Fernando Yáñez, el clérigo de Santa Olalla, se le vuelve a encontrar como testigo en 1261, esta vez en una compra, y junto a un clérigo de San Pedro, Martín Pérez. Otro de los clérigos de Santa Olalla, Domingo Martínez, repite como testigo en 1263, también en una compra, y junto a otros dos clérigos de la misma parroquia, Martín Pérez y Pedro López ${ }^{81}$. Así pues, la comunidad de Santa María de Castro se relacionaba más bien con los clérigos de la iglesia de Santa Olalla. Sólo en una ocasión aparece un clérigo de San Pedro, advocación bajo la cual se había instalado un grupo de canónigos regulares en el Monasterio de San Martín, cuya iglesia era la más próxima a Santa María de Castro, eso, a pesar de que, al menos hasta el año 1232, momento en el que se autoriza a las monjas a iniciar la construcción de su oratorio y a tener cementerio, habían estado utilizando la iglesia del mencionado Monasterio de San Martín. El conflicto que existía entre las monjas y los canónigos debió ser la causa ${ }^{82}$.

Una vez en Caleruega, y después de la bula de 1267, se comprueba en la documentación de la comunidad de dominicas la presencia de capellanes. Cómo un clérigo asumía este cargo puede conocerse a través del caso de don Benito, que cedió unas casas cercanas a las torres del monasterio, el 26 de marzo de 1272, a cambio de convertirse en capellán de las monjas, que debían encargarse de su manutención. Fueron testigos del acuerdo el diácono y el subdiácono de la villa. El mismo don Benito sirve como ejemplo para determinar algunas de las funciones desempeñadas por los capellanes, pues en 1283 aparece como testigo en una apelación, junto al capellán Juan Domingo, mientras que éste último actúa como escribano en junio de 1285 , cuando la comunidad compra unos bienes en Caleruega ${ }^{83}$. Así pues, los capellanes no se limitaban a las funciones espirituales que les habían sido confiadas en 1267, sino que intervenían tam-

\footnotetext{
78 I-1278: AMC, caj. 12, ${ }^{\circ}$ 6; $C D$, doc. CCLIV.

79 26-III-1272: AMC, caj. 7, n² 23; CD, doc. CCXLIV.

80 10-VIII-1277: Inserto en AMC, caj. 1, n 16 bis; $C D$, doc. XXIV.

81 1) 27-I-1260: AMC, caj. 7, n 21; CD, doc. CCXXI. 2) 21-IV-1261: AMC, caj. 7, n 18; $C D$, doc. CCXXII. 3) 31-VIII-1263: AMC, caj. 7, n 19; $C D$, doc. CCXXIX.

82 Sor Carmen GonzÁlez, Real Monasterio de Santo Domingo de Caleruega. Fundación de Alfonso X el Sabio, Salamanca, Editorial San Esteban 1993, pp. 25 y 27. 28-III-1232: AMC, caj. 7, n 20; $C D$, doc. CCXVI. Sobre el enfrentamiento entre la comunidad de Santa María de Castro y los canónigos de San Martín, vid. Ríos DE LA LlaVE, Mujeres de clausura ..., pp. 125-128.

83 1) 26-III-1272: AMC, caj. 7, n² 23; CD, doc. CCXLIV. 2) 12-IX-1283: AMC, caj. 6, n 24; $C D$, doc. CCLVIII. 3) 21-VI-1285: AMC, caj. 12, n 3; CD, doc. CCLIX.
}

Hispania Sacra, LX

121, enero-junio 2008, 47-65, ISSN: 0018-215-X 
bién en los asuntos temporales, tarea que, en principio, correspondía a los frailes, que no habían dejado de realizarlas.

Los capellanes no fueron los únicos clérigos presentes en el Monasterio de Santo Domingo de Caleruega en el siglo XIII. Intervinieron como testigos en los negocios jurídicos del monasterio algunos de los de las parroquias de San Esteban de Gormaz, especialmente de la de Santa Olalla, pero también de San Miguel y San Martín ${ }^{84}$. También tuvieron un papel importante los de otras poblaciones, como Arauzo de la Miel ${ }^{85}$, Santo Domingo de Silos ${ }^{86}$, Burgos ${ }^{87}$, Sepúlveda ${ }^{88}$, Hontoria de Valdearados y Baños ${ }^{89}$. Recibieron ayuda de algún eclesiástico de la corte como Sancho Pérez, arcediano de Baeza y notario de la cámara del rey Alfonso X, que además de redactar varios documentos para la comunidad, en otros fue testigo ${ }^{90}$. Igualmente los abades y monjes de los monasterios de Oña, San Pedro de Arlanza o Covarrubias, estuvieron presentes en los grandes acontecimientos de la comunidad ${ }^{91}$. En cambio, resulta notable la ausencia de los monjes de Santo Domingo de Silos, que parecen ignorar a las dominicas, a pesar de su proximidad a la villa de Caleruega.

Todo parece indicar que, en un primer momento, la comunidad de Santo Domingo de Caleruega optó por conservar el vínculo que las dueñas de Santa María de Castro habían mantenido con el clero de San Esteban de Gormaz. Esta relación desaparecería a finales del siglo XIII, cuando optaban por tratar con los clérigos de localidades vecinas y, sobre todo, de poblaciones donde las monjas tenían propiedades y por donde se extendía su dominio señorial.

En ninguno de los dos casos analizados hemos encontrado referencias directas a la intervención de los clérigos o de los capellanes en la atención espiritual de las dominicas, pero tampoco a la de los frailes, y en cambio, tal y como hemos visto, todos ellos tomaban parte en los asuntos temporales de las monjas, aunque eran los dominicos quienes tenían asignada esta función desde 1267.

84 1) 5-XII-1274: AMC, caj. 7, n 16; $C D$, doc. CCL. 2) 2-VI-1279: AMC, caj. 12, nº 2; $C D$, doc. CCLVII.

85 31-X-1266: AMC, caj. 1, n 3; $C D$, doc. IX.

86 21-II-1274: AMC, caj. 12, ${ }^{\circ} 37 ; C D$, doc. CCXLVI.

87 10-VIII-1277: Inserto en AMC, caj. $1, \mathrm{n}^{\circ}$ 16bis; $C D$, doc. XXIV.

${ }^{88}$ I-1278: AMC, caj. 12, $\mathrm{n}^{\circ} 6$; $C D$, doc. CCLIV.

89 20-VII-1292: AMC, caj. 4, n 31; $C D$, doc. CCLXIV.

${ }^{90}$ Escribano: 1) 16-VIII-1277: AMC, caj. 1, $\mathrm{n}^{\circ}$ 16; $C D$, doc. XXII. 2) 16-VIII-1277: Inserto en AMC, caj. 4, n 12; $C D$, doc. XLIV. 3) 18-VIII-1277: AMC, caj. 1, n 17; $C D$, doc. XXV. 4) 1-IX1277: AMC, caj. $1, \mathrm{n}^{\circ}$ 20; $C D$, doc. XXVI. 5) 1-IX-1277: AMC, caj. $1, \mathrm{n}^{\circ} 21 ; C D$, doc. XXVII. Testigo: 1) 31-XII-1276: Inserto en AMC, caj. 7, n 15; CD, doc. CCLII. 2) 1-VIII-1277: AMC, caj. 13, $\mathrm{n}^{\circ}$ 51; $C D$, doc. CCLIII. 3) 10-VIII-1277: Inserto en AMC, caj. 1, nº 16bis; $C D$, doc. XXIV.

91 1) 31-X-1266: AMC, caj. 1, n 3; $C D$, doc. IX. 2) 11-VII-1270: AMC, caj. 1, n 4; $C D$, doc. XIII. 3) 10-VIII-1277: Inserto en AMC, caj. 1, n 16bis; CD, doc. XXIV. 
El reparto de funciones no fue, por tanto, aplicado de forma estricta. Por otro lado, y dado que la presencia de religiosos ajenos a la Orden dominicana es anterior al año 1267, se podría deducir que la decisión sobre dicho reparto simplemente trató de clarificar la labor que, antes de esa fecha, venían realizando ciertos clérigos en algunos monasterios como los de Madrid y San Esteban de Gormaz. Ante la incertidumbre sobre su situación en la Orden de Predicadores, las monjas de ambas instituciones se habrían visto obligadas a buscar ayuda entre el clero secular. Esta costumbre no se interrumpió cuando los frailes asumieron el papel que se les asignó en 1267. El ejercicio de la cura monialium lo realizaban al mismo tiempo frailes predicadores y otros clérigos locales, más próximos a las comunidades femeninas, o relacionados con instancias de poder, y a los que se pedía su intervención cuando era necesaria, para cuestiones de tipo espiritual o para resolver los asuntos temporales, sin observar de forma estricta la distinción de funciones.

\section{CONCLUSIONES}

Aunque Santo Domingo de Guzmán mostró un claro interés por el desarrollo experimentado por la espiritualidad femenina, promoviendo la formación e integración de comunidades monásticas para mujeres en la Orden de los Frailes Predicadores, los dominicos trataron de evitar cualquier tipo de obligación hacia todas aquellas monjas que pretendían formar parte de ella. Eso planteó el problema de la cura monialium. Las comunidades de monjas dominicas del reino castellano-leonés no fueron ajenas a ésta cuestión, determinante a la hora de conseguir su pleno reconocimiento como parte de la Orden de los Frailes Predicadores, como queda expuesto en el presente trabajo, mediante el análisis de dos casos concretos, las comunidades de Santo Domingo el Real de Madrid y Santa María de Castro en San Esteban de Gormaz, luego trasladada a Caleruega bajo la advocación de Santo Domingo.

A pesar de la decisión del propio fundador de la Orden de los Frailes Predicadores de confiar el cuidado de las monjas de Madrid a su propio hermano, la asistencia de los frailes dominicos fue bastante desigual, en consonancia con la tónica general de la Orden respecto al problema de la cura monialium. No se restableció plenamente hasta el año 1258. En el caso de la comunidad de Santa María de Gormaz, ni siquiera después de su aceptación oficial en la Orden, en 1262, hubo frailes. Estos sólo empezaron a mostrar interés por las monjas una vez que se inició el proceso de traslado a Caleruega, a partir de 1266.

Mientras, fueron probablemente clérigos del entorno más próximo a ambas comunidades, o con cierta influencia, los que se ocuparon del cuidado de las monjas, como vemos por su presencia habitual en los negocios de los dos mo- 
nasterios. Esta labor prosiguió durante la segunda mitad del siglo XIII, cuando, en el año 1267, quedó institucionalizado el reparto de competencias entre frailes y clérigos seculares, correspondiendo a los primeros la atención en los asuntos temporales, y a los segundos, el cuidado espiritual. Parece también evidente que el reparto de funciones no se llevó a cabo de una forma estricta, pues las dominicas acudían a unos y otros indistintamente, tal y como prueba la participación de unos y otros en los negocios jurídicos de las dos comunidades. 